\title{
A FORMAÇÃO ÉTICA PROFISSIONAL DOCENTE: significados, trajetórias e modelos
}

\author{
Sheyla Maria Fontenele Macedo' \\ Ana Paula Viana Caetano²
}

\section{RESUMO}

O artigo é parte do resultado da tese doutoral intitulada A formação ética profissional do pedagogo na realidade brasileira. Um estudo de caso, apresentada na Universidade de Lisboa (UL), no Instituto de Educação (IEL), no ano de 2018. Tem como objetivo geral compreender a ética como dimensão estrutural da formação profissional na esfera da docência. A metodologia adotada é de caráter qualitativo, de cunho bibliográfico. A temática é inovadora, tendo sido a tese, inclusive premiada por aquela Universidade. A pesquisa foi organizada em dois subtítulos, em que no primeiro é revelada a rota que denota a interface entre a ética, a ética profissional e a formação, em que é a ética declarada enquanto competência macro e transversal. No segundo momento, são apresentados modelos formativos no terreno da ética profissional, em que ensaios e experiências na esfera da docência se destacam, evidenciando-se as pesquisas realizadas em Portugal. $O$ resultado proeminente deste trabalho se consolida com base na originalidade da temática no terreno da formação inicial de professores, e por mostrar a necessidade de que as formações integrem a ética profissional, de modo que as sociedades herdem profissionais que tenham um efetivo compromisso com a educação.

Palavras-chave: Formação. Ética profissional. Docência.

\section{TEACHER PROFESSIONAL ETHICAL FORMATION:}

meanings, trajectories and models

\begin{abstract}
The article is part of the result of the doctoral thesis entitled The professional ethical education of the pedagogue in the Brazilian reality. A case study, presented at the University of Lisbon (UL), at the Institute of Education (IEL), in 2018. Its general

1 Doutora em Educação pelo Instituto de Educação da Universidade de Lisboa (IE-Ulisboa), Professora Adjunta da Universidade do Estado do Rio Grande do Norte (UERN), Campus Pau dos Ferros, Pau dos Ferros, Rio Grande do Norte, Brasil. Orcid: http://orcid.org/0000-0002-79734773. E-mail: sheylafontenele@yahoo.com.br

2 Doutora em Ciências da Educação pela Universidade de Lisboa (UL), investigadora integrada da UIDEF, Professora Associada, Instituto de Educação, Universidade de Lisboa (IEUlisboa), Lisboa, Portugal. Orcid: http://orcid.org/0000-0003-2481-5215 E-mail:
\end{abstract} apcaetano@ie.ulisboa.pt 
objective is to understand ethics as a structural dimension of professional training in the sphere of teaching. The adopted methodology is of qualitative character, of bibliographic nature. The theme is innovative, having been the thesis, even awarded by that University. The research was organized in two subtitles, in which the first reveals the route that denotes the interface between ethics, professional ethics and formation, in which ethics is declared as a macro and transversal. In the second moment, formative models is presented in the field of professional ethics, in which essays and experiences in the teaching sphere stand out, highlighting the research carried out in Portugal. The prominent result of this work is consolidated based on the originality of the theme in the field of initial teacher formation, and by showing the need for training to integrate professional ethics, so that societies inherit professionals who have an effective commitment to education.

Keywords: Formation. Professional ethics. Teaching.

\section{LA FORMACIÓN ÉTICA PROFESIONAL:}

\section{significados, trayectorias y modelos}

\section{RESUMEN}

El artículo es parte del resultado de la tesis doctoral titulada La formación ética profesional del pedagogo en la realidad brasileña. Un estudio de caso, presentado en la Universidad de Lisboa (UL), en el Instituto de Educación (IEL), en 2018. SU objetivo general es entender la ética como una dimensión estructural de la formación profesional en el ámbito de la enseñanza. La metodología adoptada es de carácter cualitativo, de naturaleza bibliográfica. El tema es innovador, habiendo sido la tesis, incluso premiada por esa universidad. La investigación se organizó en dos subtítulos, en el primero se revela la ruta que revela la interfaz entre ética, ética profesional y la formación, en el que la ética fue declarada como una competencia macro y transversal. En el segundo momento, se presentan modelos de formación en el campo de la ética profesional, en los que se destacan ensayos y experiencias en el ámbito de la enseñanza, destacando la investigación realizada en Portugal. El resultado sobresaliente de este trabajo se consolida en función de la originalidad del tema en el campo de la formación inicial del profesorado, y al mostrar la necesidad de formaciones para integrar la ética profesional, de modo que las sociedades hereden profesionales que tengan un compromiso efectivo con la educación.

Palabras llave: Formación. Ética professional. Docencia.

\section{INTRODUÇÃO}

artigo intitulado A formação ética profissional docente: significados, trajetórias e modelos, tem a intenção de revolver compreensões acerca da ética enquanto dimensão estrutural da formação profissional na esfera da docência. Este trabalho é um recorte da tese premiada pela Universidade 
de Lisboa, no ano de 2019: A formação ética profissional do pedagogo na realidade brasileira. Um estudo de caso, e apresentada na Universidade de Lisboa (UL), no Instituto de Educação (IEL), no ano de 2018. Este trabalho se condensa como de caráter qualitativo e de cunho bibliográfico.

O interesse em desvelar a ética enquanto dimensão necessária na formação de professores, advém da percepção, enquanto docentes e pesquisadoras, de que há uma lacuna no campo, nas discussões e no universo praxiológico que envolve o saber-fazer do professor. A ética pareceria assim como no conto da Bela Adormecida, cuja protagonista de nosso texto adormece nas entranhas da floresta epistemológica da formação, aguardando o tempo, o espaço e a hora de despertar.

$\mathrm{O}$ artigo foi organizado em dois subtítulos. Na primeira parte busca-se definir a ética, a ética profissional e a concepção de formação.

Ética é um conceito multifacetado, interpenetrado de ideias, discursos, em que é muitas vezes associado como sinônimo de moral. Sua concepção, entretanto, não se afasta dessa, já que a moral retrata o conjunto dos fundamentos, normas, atitudes, hábitos, que regulam os comportamentos nas diferentes sociedades. Já ética, se consolidaria como a atitude reflexiva e sensível acerca de si, em prol do bem comum e em direção à recontextualização dessa mesma moral. Alguns conceitos nessa linha reflexiva são trazidos à tona, em especial as concepções de Abbagnamo (2007), da ética enquanto ciência da conduta; Vásquez (2000) que relaciona a ética enquanto uma experiência histórico-social no terreno da moral; Rios (2011) que nos remete a ética como uma reflexão crítica sobre a moralidade e Macedo (2018), cujas pesquisas apontam em direção à premência de uma formação ética profissional robusta, especialmente nos cursos de licenciatura, nomeadamente o de Pedagogia, lócus do acontecer dessa investigação. No que tange à ética profissional, esta se apresenta como decorrente da ética pessoal, porém, direcionada ao contexto profissional, sendo delineada por Ricoeur (2011) enquanto "sabedoria prática". O bloco é finalizado a partir das ideias de Macedo e Caetano 
(2017) da ética profissional enquanto competência autônoma e macro nas entranhas da atividade laboral.

A concepção de formação foi apresentada no sentido de embasar a ética profissional enquanto processo formativo. A formação corresponderia a um processo educacional, de natureza estruturada, com intenções predefinidas, e condicionada por fatores diferenciados, revelando-se como imprescindível à profissionalização, sendo relevadores, nesse sentido, os contributos de Garcia (1999).

$\mathrm{Na}$ segunda parte do trabalho, são trazidos alguns modelos de formação no campo da ética profissional a partir das obras de Escudero (2011), Ozar (2000), Moratalla (2001) e Feio (2015). Destaca-se ainda, no bojo das discussões, o projeto de investigação-formação sobre a temática Pensamento e Formação Ético Deontológicos de Professores, do Instituto de Educação, da Universidade de Lisboa, Portugal, em que a partir do ano de 2006, em que buscou-se mapear o pensamento ético-deontológico dos professores e seus anelos de formação, investigação essa conduzida pelas pesquisadoras Estrela e Caetano (2010).

Os modelos nos remetem à reflexão acerca da possibilidade quanto à elaboração de situações e processos formativos sob a égide de diferentes e criativas configurações.

O texto se apresenta como original, já que está direcionado ao campo da ética profissional, e consideramos que sua leitura remeterá a não poucas análises sobre o vazio que ainda se instaura nos cursos de formação de professores, que carecem de repensar esse componente em seu contexto curricular.

\section{1 ÉTICA, ÉTICA PROFISSIONAL DOCENTE E FORMAÇÃO}

Ética, como defini-la? É o mesmo que moral? E por que tantos estudiosos se debruçaram na intenção de delinear uma definição, já que se trata de um conceito multifacetado de sentidos? Qual a melhor rota a tomar 
em direção a sua significação? No que tange à formação docente é preciso delinear alguma posição epistêmica, por quê?

Abbagnamo (2007) definiu a ética como ciência da conduta (p.380) e a moral como "objeto da ética, conduta dirigida ou disciplinada por normas, conjunto dos mores" (p.682), revelando uma área de intersecção, ao mesmo tempo em que delimitou os referidos campos estabelecendo o primado da primeira sobre a segunda. Importante aqui refletir que a ética como ciência da conduta tem se legitimado no campo da racionalidade científica, o que significa que se abriram portas para um novo paradigma: o de seu posicionamento como saber teórico-prático, ativo. Isso a faz distanciar-se da perspectiva eminentemente contemplativa, sob o estigma de que ética seria coisa para filósofos, especulação advinda do senso comum, de visão reducionista, dado que a Filosofia é, inclusive, imprescindível para a formação humana. Jargão que também impingiu à ética um lugar de menor prestígio na sociedade. Afinal, para muitos a ética não se aprende na escola ou na universidade, se exercita a partir do exemplo, especialmente na família, restringindo ainda mais o campo de sua ação formativa. Não discordamos ser o exemplo de fundamental relevância no ensino da ética. Afinal, o exemplo corporeificado, conforme enuncia enfaticamente Freire (1996), se consubstancia ao caráter. O mesmo procede no que se relaciona ao contraexemplo: "Todo ensinamento moral não avalizado com o exemplo de quem o profere, atua em sentido contrário na alma do que o recebe. Este é um fato tão evidente que ninguém ousará pô-lo em dúvida". (PECOTCHE, 2008, p.80). Entretanto, não podemos concordar que a ética tão somente se ensina pelo exemplo, seria o mesmo que desconsiderar os inúmeros ensinamentos que vivenciamos rotineiramente nas experiências de vida.

Complementando as ideias apresentadas, chamamos atenção para as concepções de Vásquez (2017) sobre a ética e a moral:

A ética não cria a moral. Conquanto seja certo que toda moral supõe determinados princípios, normas ou regras de comportamento, não é a ética que os estabelece numa 
determinada comunidade. A ética depara com uma experiência histórico-social no terreno da moral, ou seja, com uma série de práticas morais já em vigor e, partindo delas, procura determinar uma essência moral, sua origem, as condições objetivas e subjetivas do ato moral, as fontes da avaliação moral, a natureza e a função dos juízos morais, os critérios de justificação destes juízos e o princípio que rege a mudança e a sucessão de diferentes sistemas morais. (VÁZQUEZ, 2017, p. 22).

Na visão de Vázquez (2017) é a partir do campo da ética que se buscaria interpretar, explicar e inquirir a moral, o que denota a estreita proximidade entre os dois campos. Em nosso entendimento, ao confrontarmos a ética com o conceito de moral, percebemos a linha fronteiriça entre as duas esferas de estudos. A ética se materializa a partir de um espaço epistemológico próprio, autônomo, terreno particular da ciência, cuja existência transcende os limites da moral, visto que sua função se estende ao campo da reflexão dessa mesma moral. Nesse sentido, consentimos com Abbagnamo (2007) de que a ética se constitui numa ciência, entretanto, não diríamos da conduta, pois nos remeteria a ideia de comportamento, o que em nosso entendimento seria encapsular a ética sob o prisma behaviorista, comportamentalista. Preferimos o termo ciência ética, pois a nosso ver a ética não precisa de maiores adjetivos, ao fazê-lo seria talvez, incorrer no risco de restringir o seu campo de ação. Portanto, a expressão ciência ética aqui não se encontra ao acaso. A ética é, portanto, um campo científico vista que possui um objeto de estudo próprio, que é a vida relacional de cada ser humano nos âmbitos do consigo, do com o outro, do com os espaços, do com projetos de vidas, do com a humanidade. Entendemo-la ainda como ciência porque é suscetível de ser observada, estudada, sondada, indagada, inquirida, averiguada, perscrutada. E porque possui diversos campos experimentais, em que podemos elencar: a ética social lestudo dos fenômenos éticos em pequenos ou grandes grupos sociais, tais como na família, na escola, no trabalho, na rua, no espaço público, etc.), a ética política, a ética profissional, a bioética, a antropoética, etc. Possui um corpo de conhecimentos próprios, que 
podem ser sistematizados, investigados, comprovados e cujas categorias fenomenológicas permitem ser metodizadas de forma racional e sensível. 0 termo sensível também não é empregado de forma aleatória, visto que nos aproximamos da concepção de uma ciência ética afetiva, cujo sentido se traduz na forte ligação respeitosa com e perante a vida. Ciência, portanto, embutida e vinculada ao cotidiano das vidas humanas. A ética é uma ciência, mater, por assim dizer. E que faz conexão com as demais áreas do conhecimento. É ainda a ciência que recorre aos valores da prudência, da sensatez, permitindo que o pesquisador, embutido dessas condições, estabeleça um olhar responsável perante o seu objeto de estudo. Por outro lado, quando se prioriza a razão em detrimento da sensibilidade, o homemcientista torna-se duro, incapaz de se comover-se independente do estímulo a que seja submetido, propenso dessa forma à perversidade. Inúmeras são as narrativas nesse sentido contadas pela história humana.

Sobre ética, Rios (2011) referenda que: "A ética se apresenta como uma reflexão crítica sobre a moralidade, sobre a dimensão moral do comportamento do homem". (RIOS, 2011, p.23). Nesse sentido, a ética redimensiona por meio de sua natureza reflexiva a moral presente nas atitudes, nos hábitos e nos costumes sociais humanos. Dessa forma, aquilo que é concebido como moral num grupo poderá não ser admitido como ético para uma determinada pessoa, especialmente se as regras admitidas como morais comprometerem de alguma forma o bem-estar social. Para melhor esclarecer, tomamos por moral o pensamento de Vázquez (2017), ou seja, dessa como o "conjunto de normas ou regras adquiridas por hábito. A moral se refere, assim, ao comportamento adquirido ou modo de ser conquistado pelo homem". (VÁZQUEZ, 2017, p.24). Ou seja, a moral é construída por uma comunidade, um grupo, uma cultura, uma sociedade, com vistas a cumprir uma função social reguladora dos comportamentos. Desta forma, a moral dita condutas, ao passo que a ética, não se molda ou se convenciona aos ditados do hábito ou do costume da coletividade, mas os questiona, reflete sensivelmente sobre e a respeito de. 
De nosso ponto de vista, compreendemos que a ética é mais do que uma noção, um princípio ou um fundamento, do que uma norma ou uma prescrição, mais do que um sentido de dever, é mais do que uma virtude, do que ações ou intenções relacionadas com alguém, ou para consigo, ou para com a sociedade, mais do que um campo de estudos da Filosofia. É mais do que os padrões comportamentais preestabelecidos, portanto, não pode ser encapsulada nos códigos de ética, quer sejam profissionais ou de um grupo. A ética, entretanto, é também isso tudo. E não se isenta desses contextos, mas transcende o corpo teórico apresentado. Desta maneira, descortinamos o conceito de ética que adotamos neste trabalho, o de que a ética não é a moral, mas que estuda a moral e a ela está vinculada incondicionalmente. Vislumbramos que a ética é em si o processo de humanização tão discutido por muitos. Humanização essa que perpassa pelo respeito e a dignificação da vida em todas as formas de manifestação.

Passemos a ética profissional. Entendemos que esse conceito se encontra literalmente interligado à concepção de ética apresentada, sendo eixo deste arcabouço, mas que, entretanto, são campos distintos em teoria e ação.

A ética profissional se diferencia pelo fato de ser o que denominamos neste trabalho de ética da práxis, que seria o estudo sobre a ética num âmbito específico e sua aplicabilidade nesse meio, neste caso o mundo do trabalho. A assertiva nos remete ainda, no que diz respeito à esfera do prático, a ideia de Ricoeur (2011) sobre "sabedoria prática": "sabedoria ligada ao juízo moral em situação e para a qual a convicção é mais decisiva que a própria regra. Tal convicção não é, todavia, arbitrária na medida em que lança mão aos recursos do sentido ético mais originário que não passaram pela norma". (p.15).

A ética aplicada ao exercício profissional não é a mesma da que se desenvolve na família, na escola, ou em outras instituições ou relações. Deve ser pensada e contextualizada no corpo de uma formação direcionada à práxis de uma profissão. Outro ponto de reflexão é o de que, a ética profissional tão pouco pode estar aprisionada ou ser tomada como matéria 
restrita aos códigos de ética, em suma, a questões de ordem deontológica. A deontologia é uma das áreas de conhecimento da ética, que se concretiza na epistemologia dos deveres, dos direitos, e que se debruça a partir do domínio da ética normativa, o que abrange o estudo das normas, das regras comportamentais, etc., e inclui sob esses contextos, a imersão de um olhar crítico sobre a dimensão sócio política que os alinhava. Quando a deontologia se volta para o campo profissional, ela se desprende e toma o contorno de deontologia profissional, encampando questões relativas as profissões ou a uma determinada profissão, em que as discussões se afunilam em torno dos comportamentos éticos previsíveis para os espaços profissionais, das relações estabelecidas entre os direitos e os deveres, dos códigos de ética, dos valores da cultura profissional (exemplo, a confidencialidade), dentre um elenco de temas que poderiam aqui ser abordados. Neste sentido, tomamos o cuidado de não enclausurar a ética profissional no corpo epistemológico da deontologia, menos ainda nos códigos de ética, insistimos nesse ponto. Isso porque, em nossa compreensão os códigos de ética se constituem em uma das bases para a construção de uma profissão em consonância com os anseios do que a sociedade espera de um profissional: bons serviços prestados. O que inclui o melhor servir, o bem servir. Entretanto, os códigos de ética precisariam traduzir o resultado das discussões coletivas, decorrentes do pensar e sentir acerca do que as classes profissionais pretendem e entendem sobre o significado da cultura do bem servir, do bom serviço prestado, ou do contrário, são construções alienadas.

Destacamos como um dos conhecimentos relevantes na esfera da ética profissional, o da compreensão que se produz entre direitos e deveres, os quais compreendemos como:

Dever/Direito. Pólos da esfera moral. Uma moralidade unicamente de deveres impõe sacrifícios sem recompensas, e uma moralidade unicamente de direitos encerra privilégios. Ambas são injustas e incompatíveis com uma ordem social sustentável. Isto exige uma moralidade onde os direitos implicam deveres e vice-versa. Por exemplo, o direito ao voto implica o dever de votar regular e responsavelmente. E o dever de manter os próprios filhos implica o 
direito de ganhar recursos para cumprir com este dever (BUNGE, 2005, p.46).

Logo, não há deveres sem direitos, e o inverso seria um contrassenso. Entretanto, parece-nos que a história do ser humano tem demonstrado o divórcio entre os direitos e os deveres. No campo profissional é comum identificar o estabelecimento de uma esgrima oculta nesse sentido. Instituições, empresas, etc., lutam pelo cumprimento dos deveres dos trabalhadores, os trabalhadores por seus direitos. Isso porque, os dois campos ainda não foram compreendidos como dimensões integradas. Em nosso entendimento, esse fenômeno acontece, dentre inúmeras razões - as quais não nos compete nesse trabalho aprofundar - porque a ética que prevalece na pós-modernidade é a do individualismo exacerbado.

Em forma de alinhavo, a ética profissional advém da ética. Não é um processo de eremitização (tornar-se eremita), visto que a ética profissional não se furtaria tão somente a relação com o Si, mas a integração com o outro na vinculação com o trabalho. A ética profissional divide e compartilha, e se faz de forma solidária, não solitária.

Analisaremos na sequência a ética profissional enquanto formação na esfera profissional. Tarefa que realizamos a partir da ética enquanto competência macro e transversal no contexto formativo.

Inicialmente é preciso discorrer a concepção de formação que alinhamos neste trabalho.

Formação não é um termo que pode ser confundido com educação, instrução, cultura, preparo, perícia, conhecimento, saber, dentre outros. Entretanto, tudo isso é corpo estrutural de uma formação, especialmente no que tange à dimensão profissional. A formação neste sentido, corresponde a um processo que a priori se organiza de forma estruturada e intencional, configurando-se enquanto estratégia imprescindível para o aperfeiçoamento, a maestria, o desenvolvimento de competências e do know-how, nas diferentes áreas do conhecimento, dos 
saberes, das atitudes, etc. no terreno de uma profissão. Sob este ponto, Garcia (1999) complementa que:

[...] o conceito formação inclui uma dimensão pessoal de desenvolvimento humano global que é preciso ter em conta face a outras concepções eminentemente técnicas. (...) o conceito formação tem a ver com a capacidade de formação, assim como a vontade de formação. Quer dizer, é o indivíduo, a pessoa, o responsável último pela ativação e desenvolvimento de processos formativos, isto não quer dizer, já o afirmamos, que a formação seja necessariamente autônoma (p. 21).

Em outros termos, a formação possui uma componente pessoal forte, em que é a pessoa a responsável pelo desenvolvimento da vontade de formação, ou seja, é esse o primeiro passo para que uma formação não se reproduza enquanto processo de alienação.

Sobre os modelos de formação, é importante compreender que se tratam de protótipos, arquétipos e que não podem se configurar em moldes, fôrmas ou medidas que engessem a criatividade dos processos formativos, mas que indiquem possibilidades de roteiros a serem postos em marcha. Entendemos que visam de forma geral desenvolver competências a fim de serem mobilizadas no exercício profissional. Sobre esse conceito, nos fundamentamos na dimensão apresentada por Perrenoud et al (2001):

\begin{abstract}
Sem nos fecharmos a priori em uma terminologia específica, consideramos aqui sob a expressão "competências profissionais" um conjunto diversificado de conhecimentos da profissão, de esquemas de ação e de posturas que são mobilizados no exercício do ofício. De acordo com esta definição bem ampla, as competências são, ao mesmo tempo, de ordem cognitiva, afetiva, conativa e prática (p.12).
\end{abstract}

Compreendemos que a esses quatro campos elencados - o da cognição, do afeto, da conatividade (função organizadora dos textos postos ao receptor de uma mensagem) e da prática - que delineiam as competências, deveria ser integrada à dimensão ética, visto que no mínimo, se articula com as demais, e auxilia na compreensão do dever e do papel que a pessoa assume enquanto profissional. É a partir desse ponto que as nossas reflexões se aproximam as premissas teóricas de de Macedo e 
Caetano (2017) que argumentam que a ética deve ser compreendida na estrutura de uma formação profissional como uma competência macro, autônoma, autossuficiente e dimensão permeadora, ou seja, transversal das demais competências. Enquanto "práxis transversal" (p.636) interage e se agrega as demais competências em quaisquer que sejam as atividades profissionais. Assim, um profissional da educação que esteja a elaborar um planejamento de ensino, um projeto, uma avaliação ou mesmo a preparar materiais didáticos para compor sua prática, contará com a dimensão ética presente nos trâmites de seus pensamentos e de suas ações, combinando-se as demais destrezas na realização de uma ou mais atividades. No que tange a ética como competência macro, autônoma, essa seria uma das metas da formação profissional, visto que a ética é dimensão estruturante da condição humana em sua configuração bio, psico, sócio e espiritual (PECOTCHE, 2008). Portanto, um bom profissional seria aquele cujo pensar, sentir, agir se fundamentam no princípio ético, sob o escopo da perspectiva humanista. Sob o humanismo, já o dimensionamos como a condição de bem, da pessoa para o coletivo e vice-versa, em prol da comum-unidade (comunidade). Importante também recordar que o cerne da atividade educativa está apoiado nesse sentido e que sob essa ótica, a docência necessitaria se edificar. Na rota de Macedo e Caetano (2017) compreendemos que a ética profissional é uma competência autônoma e macro da competência profissional, e que de acordo com as autoras, se sustenta na seguinte triangulação:

a) Conceitual e axiológica, do que se pensa, compreende e valora, a partir do campo conceitual; b) Deontológica, a ética do dever e dos princípios definidos apriori nomeadamente no campo profissional; c) Contextualista e consequencialista, do que se entende ser ético num contexto particular, atendendo às circunstâncias e às consequências previsíveis da ação (p.638).

O que denota que toda a formação deveria perpassar necessariamente por quatro eixos estruturais: 1. Conceitual, do que se 
entende ser a ética; 2. Axiológico; 3. Deontológico; 4. Contextualista/consequencialista.

O eixo conceitual nos remete à reflexão sobre as representações que se possui sobre o que significa ser ético. Em outras palavras, o que profissionalmente consiste em ser ético. Essa forma de estar na profissão faz toda a diferença nos espaços e estruturas laborais. Entretanto, compreendemos que essa posição poderá ser relativizada a partir de vários aspectos, quer seja do ponto de vista do que a escola, a universidade, a comunidade escolar ou ainda o próprio profissional concebam ser a ética enquanto competência necessária ao seu saber-fazer.

Destacamos o eixo axiológico como alicerce intrínseco à profissão docente, e que nos projeta ao terreno dos valores éticos. Neste ínterim, é preciso refletir inicialmente sobre o ponto de vista que dimensionamos a ideia de valor nesta pesquisa, e que se baseia enquanto grandeza de qualidade positiva. Macedo (2018) ratifica essa visão e inferencia sobre o campo axiológico que:

[...] os valores são agentes psíquicos positivos que se gestam no interno do ser humano e que se originam a partir da reflexão ética, conformando-se em parte do caráter de uma pessoa. Dessa forma, é com base em valores que as pessoas são adjetivadas como generosos, fiéis, honestas, etc. Os valores têm como principal função a defesa do ser humano em relação a tudo o que entorpece a convivência nos âmbitos moral e ético nos mais diferenciados ambientes em que convive. Os valores são como escudos psíquicos, e que cumprem ainda o papel na defesa de condutas inadequadas, ao mesmo tempo em que se configuram numa fortaleza, fazendo-se de muralhas na proteção contra experiências adversas que a vida apresente (p.105).

Logo, cada profissão priorizará certos valores éticos (MACEDO, 2018), e no que tange à docência, cada contexto, espaço e experiência exigirá a assistência mais deste ou daquele valor. Conforme o preconizado no eixo seguinte.

Avançamos para o eixo contextualista/consequencialista, já que fizemos menção à deontologia em outra passagem do texto. O eixo permite compreender que uma mesma conduta em contextos de tempo e espaços diferenciados gera consequências e reflexões éticas distintas, ou seja, o que 
pode ser ético numa época, nem sempre o será em outra. Além dessa questão temos ainda que, culturas profissionais diversas, que vivem num mesmo tempo e espaço e que podem em experiências similares não concretizar uma mesma tomada de decisão ética. Tomemos um exemplo no campo da educação. Imaginemos duas escolas com culturas escolares diferenciadas e em que numa delas a avaliação seja mediada por notas e na outra por conceitos. Um mesmo estudante que tenha obtido um determinado rendimento escolar poderia vir a obter resultados desiguais em contextos escolares que vislumbrem a avaliação sobre concepções diferenciadas. Nesse sentido, até a apreciação de sua produção perpassaria por julgamento de valores distintos, o que envolveria, dentre outros fatores, a dimensão ética.

Sobre a ética profissional enquanto competência macro, autônoma e transversal das demais competências do campo profissional, entendemos que a mesma está associada a um ideal de serviço, em que o sentido de bem não pode ser desagregado, é o que caracteriza o profissionalismo de qualquer trabalhador. Para melhor compreensão dos aspectos apresentados, e a fim de evitar que se enverede pelo encantamento do canto da sereia, se faz oportuno recordar as palavras de Rios (2011) de que o fazer bem (dimensão técnica) e o bem fazer (dimensão política) estão embutidos em quaisquer atividades profissionais, o que nos permite ainda ratificar a ética profissional como competência mediadora:

A ideia de bem parece-me significativa na definição de competência, porque ela aponta para um valor que não tem apenas um caráter moral. Ele não se desvincula dos aspectos técnicos nem dos aspectos políticos da atuação do educador. É nessa medida que se pode compreender, como veremos, a ética como mediação (RIOS, 2011, p.48, grifos nossos).

É notório que cada pessoa ou grupo poderá ter um entendimento do que venha a ser a ética, porém, o sentido de bem que assinalamos pressupõe a interação entre as duas dimensões apresentadas por Rios (2011) e cujo sentido se distancia do estereótipo do ser bonzinho - o que poderia levar a uma prática profissional ética permissiva e reducionista. 
Em tom de arremate, pode-se inferir que a ética se liga ao conceito de bem, na perspectiva humanista enunciada e vinculada à atitude consciente, do bem pensar, sentir e agir com-ciência desse mesmo bem, consistindo numa dimensão que se integra à configuração da pessoa, e num componente que favorecerá a que se chegue a uma compreensão agregadora sobre a formação ética no campo profissional docente.

\section{MODELOS DE FORMAÇÃO ÉTICA PROFISSIONAL NO TERRENO DA DOCÊNCIA}

Apresentamos neste bloco temático alguns modelos, trajetórias e ensaios no corpo da formação ética profissional. Os modelos, via de regra, assumem no imaginário coletivo as concepções de molde, forma, fôrma, medida, matriz, dentre outras. Nossa intenção, entretanto, é a de que possamos acolher a intenção de encampar, de incluir a ciência ética como parte de nossas formações, e não apontar este ou aquele modelo como rota, mas sim, que a partir dessas vivências elaboremos o nosso próprio caminho.

A ética profissional docente é apontada por Escudero (2011) como "um terreno singular atravessado por tensões, dilemas e decisões fundamentadas e razoáveis em que há que se construir, contrastar com múltiplas realidades e contextos de reflexão e diálogo em diversas esferas e distintos agentes". (p.95, tradução nossa). Defende, portanto, não uma ética em particular, mas plural, em que várias éticas interagem entre si, nomeadamente: a ética da justiça, a ética crítica, a da profissionalidade, a do cuidado e a ética comunitária democrática. É com base neste entendimento que assinala que a ética profissional do professorado se constrói a partir da figura 1, não se constituindo seu esquema em necessariamente um modelo de formação, mas que certamente promove reflexões a respeito da questão (Figura 1): 
Figura 1 - Ética profissional do professorado

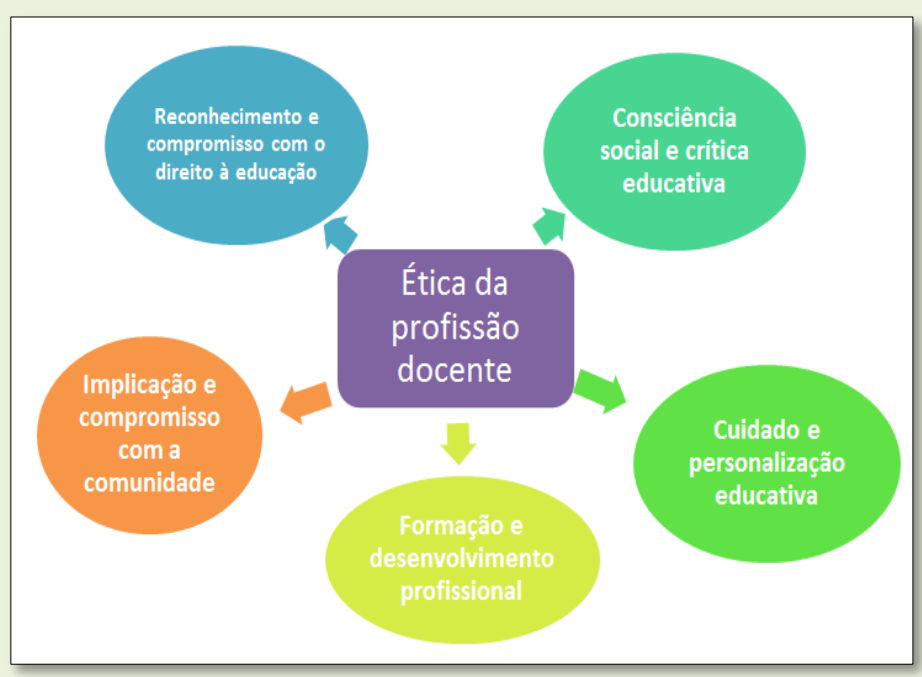

Fonte: Escudero (2011, p.96, tradução nossa).

Como se pode observar, a ética profissional se apoia em cinco campos. Segundo Escudero (2011), o reconhecimento e o compromisso com o direito à educação não se encontra somente nos domínios da legalidade e das políticas públicas. É parte da função social do professor, a quem cabe não só defender esses direitos, mas forjar uma educação que se apoie numa prática "constituída por concepções democráticas sobre a escola, o currículo e o ensino que podem e devem ser devidamente interiorizados, transformados em compromissos e ações consequentes". (p.97, tradução nossa). Prática que forje condições para a criação da justiça como um princípio ético, que se vincula a outros, tais como os de equidade e democracia.

A consciência social e crítica educativa se fundamentariam na capacidade do professor de realizar uma análise apreciativa daquelas variáveis sociais e ideológicas que atuariam como erva daninha e com capacidade de corroer o espaço educacional, tais como os mecanismos ligados a uma educação de cunho reprodutivo, e que favoreceriam o avanço dos dispositivos de desigualdade e de exclusão social. Essa esfera se estenderia ainda, de acordo com Escudero (2011), a uma prestação de serviço focada na comunidade, integrando-se aos movimentos sociais, a 
partir da constituição de espaços de voz, em que a crítica da sociedade se fizesse presente.

Cuidado, apoio, responsabilidade e personalização educativa são valores que estão diretamente relacionados à ética do cuidado, discutida por Gilligan (1997), e baseada na premissa de que os relacionamentos exigem uma atenção especial e a reciprocidade. Estes valores estariam presentes a partir da perspectiva da ética feminina, sem que esta maneira de conceber a ética seja concebida como hegemônica. Suas pesquisas levantaram que o pensar feminino teria de ser percebido, e incorporado pelas pessoas, independente do gênero.

Retomando Escudero (2011), cabe chamar atenção para dois pontos, o primeiro no empenho docente no sentido do cultivo de virtudes que se aliem a essa atitude do cuidar, é citado o "amor às pessoas em formação" (ESCUDERO, 2011, p.99) e o segundo, da contribuição decisiva para que as aprendizagens se concretizem, recordando-se que cada aluno/a é um (personal), e que se faz mister personalizar 0 bem querer a cada educando/a, de forma que seja o professor um elemento facilitador nesse processo.

A implicação e o compromisso com a comunidade se apoiariam na instituição de um diálogo permanente com o grupo escolar, a família do aluno/a e a comunidade. Ou seja, fazer valer a "implicação ativa na vida, na deliberação, nas decisões e no projeto pedagógico do centro em que trabalha". (ESCUDERO, 2011, p.101). Esse campo da figura delineada se alicerça ainda no fato de que, não há ética humanista na postura de ensimesmar-se nas paredes das salas em que as aulas se fazem. Isto seria desconsiderar a responsabilidade firmada no que se refere ao próprio papel do professor nos espaços institucionais em que o labor educativo se incrementa.

Deixamos a componente formação e o desenvolvimento profissional para uma análise final da figura, pelo fato de termos questionado sobre as razões da manutenção desse item no mesmo patamar hierárquico dos demais. Intencionamos compreender ainda as causas que motivaram 
Escudero (2011) não ter incluído os pontos anteriores no arcabouço formativo, uma vez que compreendemos que são fundamentos naturais para um modelo de formação ética profissional. Percebemos que sua intenção talvez tenha sido a de realizar um chamamento para as quatro outras esferas apresentadas, que caso compusessem 0 alicerce da formação, poderiam passar despercebidas.

A formação ética defendida na figura 1 se sustenta no desenvolvimento de conhecimentos intelectuais, propósitos morais consolidados, capacidades docentes (como a de ativar a reflexão moral) e o cultivo de virtudes necessárias ao exercício de uma profissão. As virtudes, careceriam de ser criadas, evidencia Escudero (2011). Contudo, a materialização desse acontecimento estaria atrelada à necessidade de uma formação inicial que contemplasse a ética como um "imperativo" ( $p$. 100) em sua profissão, ou seja, de que "cada professor e professora tome em suas próprias mãos como um imperativo ético, longe de considerá-lo, pois, como algo cosmético, imposto, exigido formalmente, em tempo livre e remunerado" (ESCUDERO, 201 1, p. 100, tradução nossa). O imperativo ético nos remeteria ainda à reflexão de que é direito que todo profissional da educação tenha uma formação de qualidade, ou seja, ser bem formado e formado para o bem, o que implicaria num componente de ordem ética que não fosse de natureza oculta.

Ozar (2000) discute o problema da educação ética na formação inicial e não somente para a formação de professores. Apresenta uma abordagem centrada nos objetivos voltados para a aprendizagem denominada Ethics Across the Curriculum [EAC]. Em seu entendimento, sua proposta de formação é aplicável a diferentes cursos, para os quais indica uma revisão dos programas curriculares. Nesse sentido, se apoia nas premissas teóricas do psicólogo Rest et al (1999) distinguiram quatro aspectos da vida moral, os quais Ozar (2001) sintetizou num desdobramento em quatro áreas e defendia que as mesmas deveriam ser inclusas nos currículos de formação ética profissional. Sendo essas: 1. Consciência; 
2.Raciocínio/Habilidades reflexivas; 3. Motivação/ Convicção; 4. Implementação.

Rest et al (1999) entenderam que a consciência remete a um estado de lucidez mediante uma linha de valores/princípios/ideais que uma pessoa já possuísse e que seria preestabelecida ou ampliada, e que capacitaria o profissional a agir eticamente na medida em que se articulasse sobre essa.

O tópico raciocínio/habilidades reflexivas se refere ao desenvolvimento de pensar logicamente e resolver questões relativas aos campos ético/moral. Quer dizer, seria a capacidade de refletir rotineiramente e transmitir para os que fazem parte de seu convívio os resultados dessa reflexão.

A motivação/convicção se resume a um estado afetivo que concebido na busca de justificações e estímulos para se levar a cabo a linha de valores/princípios/ideais estabelecidas como marco em situações laborais. E por fim, a implementação, que seria exatamente a capacidade de superar os desafios éticos nos cenários da prática.

Aconselha Ozar (2001) que para estruturar programas com base nas quatro áreas elencadas os professores formadores nos cursos de formação inicial deveriam ser os primeiros a desenvolver tais habilidades para que resultados efetivos fossem alcançados nos processos formativos.

Modelos de profissionalização em ética profissional em geral são ofertados pelas universidades e em diferentes cursos de graduação. É a partir desse espaço institucional que Moratalla (2001) apresenta três exemplos utilizados, ainda que compreenda que a ausência de um modelo também representa uma opção formativa, ou um contramodelo, diríamos, adjetivando esta brecha estrutural como um niilismo.

Para Moratalla (2001) os modelos universitários se baseiam no princípio de responsabilidade profissional, ainda que sob diferentes enfoques, visto que cada profissão exige essa atitude, esse olhar, para que se possa movimentar com sentido de compromisso, dever e comprometimento perante os dilemas éticos da profissão. Os modelos são, portanto, 
designados de: profissionalização mecanicista, profissionalidade civilizadora e profissionalização identificadora.

A profissionalização mecanicista se relacionaria a um ajuste dos planejamentos formativos aos mecanismos laborais que se sujeitam às exigências do mercado de trabalho. Em outras palavras, a universidade se posicionaria a serviço do social, da sociedade, mas singularmente, da economia. Nesse sentido, revela Moratalla (2001) que a ética profissional se subordinaria ao preparo para atingir as metas do seguinte tríplice preceito: da economia, da eficácia e da eficiência. É importante chamar atenção de que nesse modelo os programas de formação se adaptariam ao que a sociedade espera enquanto comportamentos que fluam na direção do avanço econômico, científico, tecnológico, etc. É ainda um processo de adaptação psíquica da pessoa/profissional ao cerne do utilitarismo da prestação de serviços, bem afim com o princípio durkheimiano de que os fatos sociais são exteriores aos sujeitos e que, atuam sobre esses a partir de um poder coercitivo. Ou seja, o que se prioriza é o desenvolvimento da profissional expertise, que cumpre ética e tecnicamente bem o seu papel.

Em acordo com Moratalla (2001), a profissionalidade civilizadora se prestaria a pensar a profissão sobre os moldes de um projeto de modelização econômica e de ordem cívica, em que diferente do individualismo acirrado do primeiro modelo, se teria outro, de caráter social. Abrangeria certo sentido de civismo, sobre o qual se pode incluir a preocupação na aquisição de conhecimentos voltados com forte influência para o outro, quer esteja este outro no espaço público, no privado, no familiar, etc. e que se projetaria nos diferentes ambientes: social, cultural, político, etc. Seria a ética profissional, portanto, voltada para a manutenção do bem-estar social, em que a responsabilidade profissional estaria para a pública e vice-versa.

O terceiro modelo de profissionalização identificadora ou identificante situar-se-ia na mediação entre os conhecimentos profissionais e os valores, constatando-se ainda certo distanciamento da ética profissional dos campos conflituosos da economia e da Sociologia tidos em conta nos 
modelos anteriores. Conforme explicita Moratalla (2001), os valores e a forma como estes se organizam seriam fatores determinantes nesse modelo, que não buscaria formar tão somente o especialista, o expertise, nem exclusivamente o bom cidadão, mas a pessoa no contexto de suas múltiplas relações sociais. Desta forma, os valores associados à ética profissional estariam pautados em termos das relações humanas, da dialogicidade do consigo para o outro, agregando-se a um ideal de sociedade integradora da pessoa ao social com vistas ao bem comunitário.

Nossas ideias sobre formação ética profissional se aproximam desse último modelo, visto que as duas primeiras vertentes excluem um fator que consideramos primordial, o comprometimento da pessoa frente a si, ao outro e aos diferentes grupos sociais em que convive. Já os dois modelos iniciais de formação podem ser considerados exteriores ao si. Com essa afirmativa, queremos constatar que há uma forte ruptura, um corte do exercício profissional com a própria vida. E quando esse rompimento se consolida, os laços afetivos perante aos serviços que deverão ser prestados se desconectam. Postura essa que poderá induzir a um trabalho automatizado e alienado perante o compromisso com o sentido de bem que aqui temos delineado. Cabem ainda algumas questões, como esses modelos se materializam em programas de formação? E o currículo? E como corporificar uma formação dessa natureza?

Para quiçá responder as últimas questões, descobrimos em Portugal que no ano de 2004 foi iniciado um projeto de investigação-formação sobre o lema Pensamento e Formação Ético Deontológicos de Professores, tendo o Instituto de Educação, da Universidade de Lisboa como instituição promotora e financiamento da Fundação para a Ciência e Tecnologia [FCT] a partir do ano de 2006, cujo objetivo geral foi o de caracterizar o pensamento ético-deontológico dos professores e as suas aspirações no que se refere a esta formação. O projeto foi organizado em duas fases, em que na primeira se partiu de 40 entrevistas semi-diretivas a professores de todos os níveis de ensino, consistindo-se a segunda fase do planejamento e da 
realização de experiências formativas que culminaram em modelos de formação com base em estudos de caso. (ESTRELA; CAETANO, 2010).

Cabe evidenciar que os professores ao expressarem acerca do seu campo profissional reconheceram que a sua profissão é eminentemente ética:

[...] ética porque o professor deve agir na observância de um conjunto de princípios de natureza moral e também porque o que se espera do professor é que ele recorra a uma estratégia, desenvolva um método e disponha de recursos para promover a formação ética dos alunos (CAETANO; SILVA, 2009, p.50).

Do exposto, identificamos que a possibilidade de professores refletirem sobre a forma ética de sua práxis foi um contributo de ordem relevante, especialmente em razão das lacunas existentes nesse campo de estudo. A metodologia adotada pelo grupo de investigadores incluiu dentre inúmeras ferramentas, o uso da internet para a "constituição de comunidades de reflexão ética" (ESTRELA, 2010, p.19), em que desde o início foi mantido um site para a troca das experiências acerca do projeto em construção, em que um fórum de debates foi criado, apesar de constatarem uma reduzida participação. (p.19). Dentre os inúmeros pontos positivos que poderíamos trazer acerca do projeto de investigação, destacamos a construção de um modelo de formação ética de professores, apoiado nos resultados obtidos a partir da experiência de formação e dos estudos de caso realizados, conforme evidenciado na figura (Figura 2): 
Figura 2 - Para uma modelização da formação ético-deontológica de professores

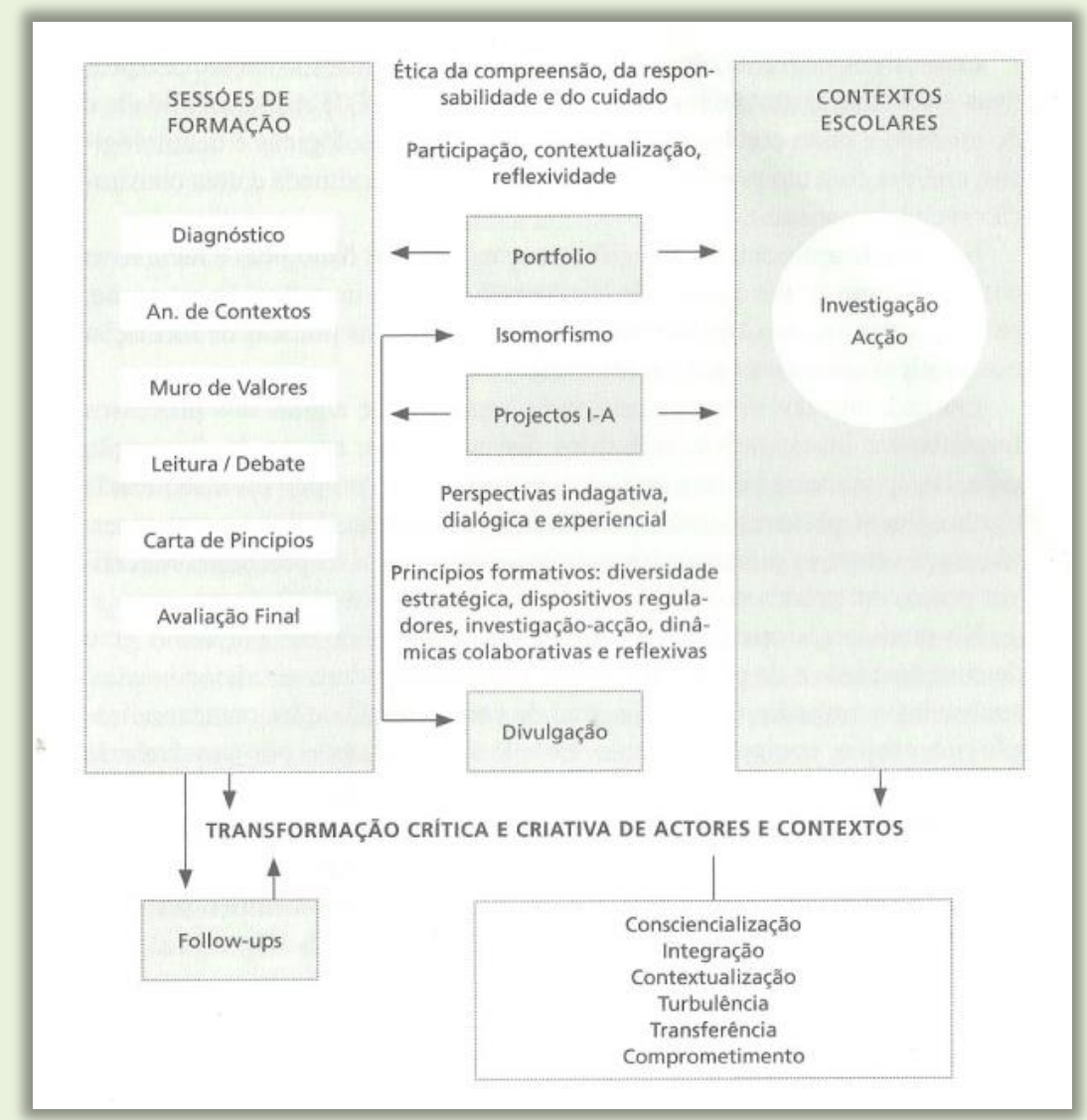

Fonte: Caetano (2010, p.169).

Expliquemos o modelo.

A metodologia denominada investigação-formação constituiu-se no alicerce do projeto investigativo sobre o pensamento ético deontológico dos professores e que inspirou o modelo formativo apresentado, projetando o perfil profissional de um professor pesquisador. Dois campos se encontram em evidência na figura, o da sessão de formação e a dos contextos escolares (espaços em que o professor atua e onde naturalmente se daria o impacto significativo da intervenção formativa), e em que se pode constatar a forte articulação entre ambos. Faz-se importante revelar que as sessões de formação aconteciam a partir de diagnósticos realizados e que mantinham o diálogo, o intercâmbio e a troca de experiências como a medula de toda a estrutura formativa, e que ainda se organizava por meio de várias ferramentas metodológicas. Nesse sentido, sublinhamos o muro de valores lque consistia no pronunciamento dos sujeitos da pesquisa acerca da 
hierarquia dos valores que consideram relevantes em sua atividade profissional) e a carta de princípios (documento construído coletivamente e que por meio de círculos de estudos intencionava enquadrar os códigos deontológicos da categoria profissional). Por detrás desses pilares, percebemos a existência de um pano de fundo que fundamentou as duas colunas (sessões de formação e contextos escolares) e que foi composto por:

1. Dois conjuntos de princípios: os primeiros seriam princípios formativos, nomeadamente - a diversidade estratégica, os dispositivos reguladores (carta de princípios), a investigação-ação, as dinâmicas colaborativas e reflexivas e que orientariam "os modos pelos quais os sistemas de formação se articulam com os sistemas de intervenção onde os professores atuam" (CAETANO, 2010, p.168), ou seja, seus contextos escolares. O segundo grupo de princípios denominado de estratégicos, seriam como as raízes dos princípios formativos elencados, de característica mais ampla, sendo estes os de participação, contextualização e reflexividade, privilegiando-se como base os enfoques indagativo, dialógico e experiencial.

2. Dimensões da intervenção formativa das mudanças decorrentes desse processo, com destaque para a consciencialização, a contextualização, a integração, o comprometimento, a turbulência (fenômenos que perturbam a ordem intervencionista) e a transferência, que seria a culminação do pensamento ético deontológico no espaço e no tempo de sua ação;

3. Perspectivas éticas da formação a serem levadas em conta como objetivo da formação do pensamento ético deontológico: ética da compreensão, da responsabilidade e do cuidado e que de acordo com os pesquisadores, se confluem pelas "vias contextualistas, teleológicas e deontológicas" (CAETANO, 2010, p. 170).

4. $O$ isoformismo como ideia da relação unívoca e do espelhamento mútuo entre as práticas de formação e as práticas educativas de professores.

A figura mantém ainda alguns pontos que costuram todas as relações, e que como os demais elementos constituintes do modelo, revelam a intencionalidade do desenvolvimento das capacidades crítica e de 
transformação dos contextos de formação, através de uma supervisão, de um acompanhamento ativo e dos projetos orientadores como técnicas interventoras "para a compreensão e transformação das suas práticas e dos seus contextos". (CAETANO, 2010, p.169). Denotam ainda os próprios pesquisadores, que o modelo assinalado, apesar de fazer notar certa linearidade na disposição dos elementos contextuais apresentados, possuiu em sua construção a intenção de que todo este processo formativo fosse permeado pelo diálogo. Compreendemos que seria esse um dos elementos fundamentais, diríamos, inclusive, a ferramenta mestra que junto à reflexão consistia no sustentáculo da formação ética profissional. Diálogo esse que teria de se aproximar das linguagens que interpenetram os conhecimentos das práticas pedagógicas, visto que nos cursos de formação inicial a linguagem de cunho filosófica tem sido privilegiada. No que se refere a esse ponto, Alonso (2006) soluciona essa querela, a da linguagem da prática profissional x a da linguagem filosófica, ao manifestar que não é a ética profissional "uma terceira linguagem entre a linguagem da profissão (ou seja, a linguagem das ciências e das técnicas em que se baseiam as habilidades e capacidades profissionais) e a linguagem da filosofia (moral)" (ALONSO, 2006, p.14). Ela será sempre um "bilinguismo". (p.14). Ou seja, a ética não poderá jamais se abster de seu conteúdo filosófico, entretanto, deverá enveredar suas construções em contextos de uma ética que aqui denominamos de praxiológica, o que nos remete a pensar sobre a formação profissional deste formador. Mais um desafio imposto para se pensar ética profissional enquanto formação.

Feio (2015) em sua pesquisa sobre formação ética de professores no cruzamento com a formação ético-moral de aluno/a sugeriu linhas orientadoras para uma formação ética profissional de professores, conforme denota a figura a seguir (Figura 3): 
Figura 3 - Modelização para uma formação ética profissional de professores

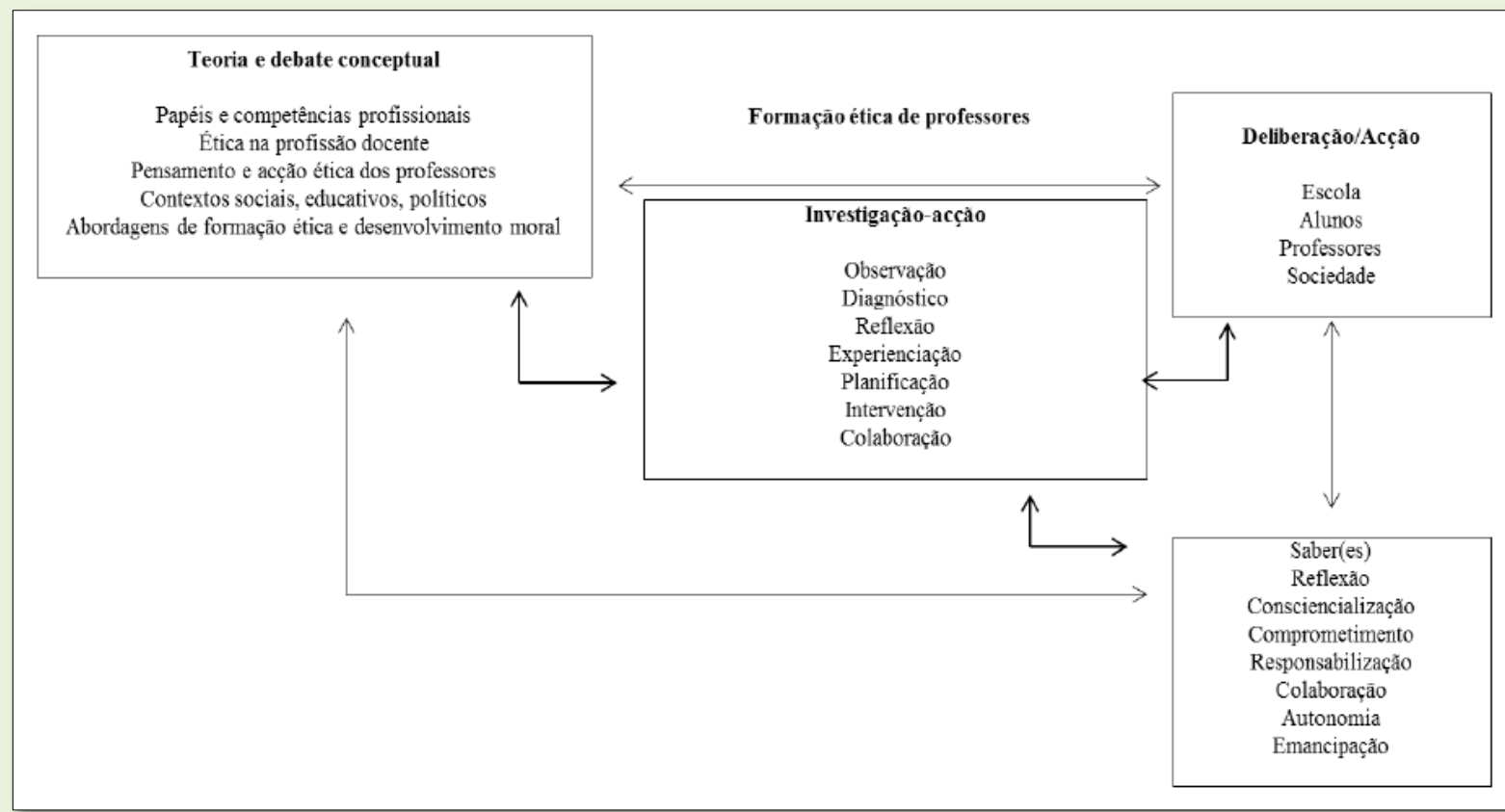

Fonte: Feio (2015, p.446).

No modelo pode-se identificar uma estreita proximidade na relação teoria e prática, intermediada pelo método de investigação-ação, que de acordo com a autora, "não dispensam, antes exigem, reflexão, experienciação, debate, observação e colaboração". (FEIO, 2015, p.447). Na formação apresentada sugeriu ainda a participação de um moderador, que interviria na superação de práticas, costumes, hábitos, padrões convencionados, quer fosse na escola ou no cotidiano profissional do professorado. Ainda segundo Feio (2015), o respectivo modelo teria de levar em conta:

1. As situações emblemáticas, incluindo o diagnóstico das questões problema sobre ética, que teriam de perpassar pelo crivo da discussão e da reflexão a nível individual/coletivo, com duração de um ou mais anos letivos. 2. A reflexão que sofreria o recorte da "experienciação de actividades (dilemas, role-playing, estudo de casos, folhas de valores, muro de valores, entre outras) e materiais concretos (textos, imagens, filmes, entre outros) para a formação ética". (p.447). Incluindo-se ainda outras atividades, tais como as oficinas, desde que estas envolvessem em seu processo as fases: diagnóstica, de observação e de análise. 
3. A exploração/incremento das técnicas reflexivas e de observação, tais como o diário de bordo, tabelas de observação, que utilizadas de forma sistemática favoreceriam a criação da ética assente na reflexão.

4. O desenvolvimento continuado de um quadro teórico que informasse as práticas e formas de abordagem acerca da formação ética dos alunos/as, incluindo os aspectos relativos à ética em si e as questões deontológicas.

5. A criação de redes colaborativas na escola e para além de seus muros, e que contasse com sujeitos externos motivadores deste processo. Há também uma referência de que estas redes teriam de "alargar-se a heteroobservação, aumentando redes de amigos críticos em diferentes momentos dos processos formativos". (FEIO, 2015, p.448). A pesquisadora se apoiou nas ideias de hetero-observação em Stenhouse (1975) em que o professor seria ao mesmo tempo investigador/observador de seu labor profissional.

$\mathrm{Na}$ peregrinação dos caminhos consagrados à formação ética profissional no campo da docência, constatamos igualmente aos pesquisadores portugueses, que há um lapso, um vazio, um vão, uma janela, uma omissão ou um espaço branco, oco no que se refere, não somente à formação inicial, mas inclusive, a "inexistência de um programa formal nesta área ao nível de formação continuada" (MOURINHA; MARQUES, 2010, p. 142), fatos que motivaram esses e os nossos estudos. Anunciamos ainda que, para além da escassez nessa esfera do conhecimento, percebemos lacunas no âmbito da Pedagogia Social, do mesmo modo, os estudos dos pesquisadores portugueses apontam outras necessidades, tais como as "relativas ao estudo de currículos de formação e ao estudo da influência do formador e das suas perspectivas de formação" (CAETANO, 2010, p.172). Rota a ser perseguida para aqueles que almejam a realizar um trabalho sério sobre a formação ética profissional no campo da educação.

\section{CONSIDERAÇÕES FINAIS}

A ética é uma dimensão que faz parte de nosso cotidiano desde que nascemos. Inclusive e comumente escutamos o jargão educação vem do berço, relacionando essa mesma educação a um conjunto de virtudes, a 
um comportamento ético de excelência. Neste trabalho revolvemos o conceito em pauta, desvelando que a ética é dimensão reflexiva, sensível, que se forja do individual para o coletivo, e vice-versa. Seu corpo epistêmico possui forte ligação com a moral e se debruça sobre essa, para além de compreendê-la, ressignificá-la. Poderíamos denominá-la enquanto ciência de si, o que em outras palavras significaria que é campo de estudos autônomo, porém, interligado a diferentes âmbitos do conhecimento. O que a justificaria enquanto competência macro e transversal.

Já a ética profissional se desprende da ética, compreendendo o campo da formação que se instaura no processo evolutivo da consciência ética no mundo do trabalho. Não envolve somente a figura do profissional, mas toda a rede laboral de uma instituição. Assumir a ética profissional como forma de estar na profissão significa ter compreendido a função social do trabalho que se empreende, independente do campo em que este se desenvolva. Entretanto, ao se tratar do profissional da educação, essa dimensão ganha um novo atributo: o da responsabilidade frente ao sucesso escolar do educando/a, já que define um ideal de serviço humanístico, com vistas a que o trabalho educacional contribua para estruturar uma nova cultura.

Uma questão relevante: como seria o acontecer de uma profissão sem um viés ético formativo? É possível, já que a ética interpenetra o todo saberfazer do professor? A ética é necessária para selecionar o currículo, as ferramentas e formatos de avaliação, é preciso dela para gerenciar recursos didáticos, fazer frutificar boas relações humanas. Logo, entendemos que, a ética ao permear o mundo do trabalho docente, permite não só que o profissional desenvolva um espírito crítico em relação ao bem pensar, sentir e o bem fazer, como também, gera o discernimento em direção à construção do bom senso, nas instituições, escolas, etc. A ética profissional é ainda responsável por criar o sentido da compreensão de que a prestação de serviços consiste em prática social viva. Assim sendo, uma profissão que não contemple a ética profissional, e uma formação profissional que negligencie 
a temática em sua matriz curricular, projetarão o evento da alienação diante do próprio trabalho.

Modelos de formação devem ser repensados e ressignificados. O mais importante em nosso entendimento, é que, experiências sejam capturadas, não na intenção de serem replicadas na íntegra ou parcialmente, mas que possam se configurar como um norte na elaboração das próprias vivências formativas, quer sejam iniciais, continuadas, etc. O fato é que, há lacunas neste campo do conhecimento e, mais do que consagrar o elemento ético enquanto componente formador, denota-se considerar que a pauta trazida até aqui é estruturante na construção da identidade docente em prol da construção de uma sociedade mais justa, equânime e humanista.

\section{REFERÊNCIAS}

ABBAGNO, N. Dicionário de Filosofia. São Paulo: Martins Fontes, 2007.

ALONSO, A. H. Ética das profissões. Tradução Silvana Cobucci Leite. São Paulo: Edições Loyola, 2006.

BUNGE, M. Dicionário de Filosofia. 3. ed. México: Siglo Veintiuno Editores, 2005.

ESCUDERO, J.M. Dilemas éticos de la profesión docente. CEE. Participación Educativa, 16, p. 93-102, marzo, 2011. Disponível em:

https://pdfs.semanticscholar.org/cc85/e55ac5b92d9b9225dd06fadaebfd51 d88f08.p df. Acesso em 20 jan. 2020.

ESTRELA, M. T.; CAETANO, A. P. (coord.). Ética Profissional Docente-Do pensamento dos Professores à sua Formação. Lisboa: Educa, 2010.

ESTRELA, M.T. Introdução e apresentação do projecto. In: ESTRELA, M. T.; CAETANO, A. P. (coord.). Ética Profissional Docente-Do pensamento dos Professores à sua Formação. Lisboa: Educa, 2010. p. 9-21.

FEIO, M. A. A formação ética de professores no cruzamento com a formação ético-moral de alunos: o papel da investigação-acção. 2015. Tese (Doutorado em Educação) - Instituto de Educação, Universidade de Lisboa, Lisboa, Portugal, 2015.

FREIRE, P. Pedagogia da Autonomia. Saberes necessários à prática educativa. 25. ed. Rio de Janeiro: Paz e Terra, 1996. 
GARCIA, C.M. Formação de professores - Para uma mudança educativa. Lisboa: Porto Editora, 1999.

GILLIGAN, C. Teoria psicológica e desenvolvimento da mulher. Lisboa:

Fundação Calouste Gulbenkian, 1997.

MACEDO, S.M.F. A formação ética profissional do pedagogo na realidade brasileira. Um estudo de caso. Tese (Doutorado em Educação) - Instituto de Educação da Universidade de Lisboa, Universidade de Lisboa. Lisboa, p.s32. 2018. Disponível em: https://repositorio.ul.pt/handle/10451/40071 Acesso em: 03 fev. 2020.

MACEDO, S.M.F.; CAETANO, A.V.P. A ética como competência profissional na formação: o pedagogo em foco. Educação e Realidade. Porto Alegre, $v$. 42, n. 2, p. 627-648, Junho 2017. Disponível em:

http://www.scielo.br/pdf/edreal/v42n2/2175-6236-edreal-56078.pdf Acesso em: 03 fev. 2020.

MORATALLA, A. D. Ética. Todo lo que usted estudió y nunca debeó olvidar (puesto al dia). Madrid: Acento Editorial, 2001.

OZAR, D. T. Learning outcomes for ethics across the curriculum programs. Teaching Ethics, v. 2, n.1, p. 1-27, 2001.

PECOTCHE, C.B.G. O Espírito. 6. ed. São Paulo: Editora Logosófica, 2008.

PERRENOUD, P.; PAQUAY, L; ALTET, M; CHARLIER, É. (orgs). Introdução. PERRENOUD, P.; PAQUAY, L; ALTET, M; CHARLIER, É. (orgs). In: Formando Professores Profissionais: Quais estratégias? Quais competências? 2. ed. Porto Alegre: Artmed, 2001.

REST J.; NARVAEZ D.; BEBEAU M.J.; THOMA S.J. (org). Postconventional moral thinking: a neo-Kohlbergian approach. Mahwah, NJ: Lawrence Erlbaum, 1999.

RICOEUR, P. Ética e moral. Tradução António Campelo Amaral. Covilhã: Universidade da Beira Interior., 2011.

RIOS, T. A. Ética e competência. 20. ed., São Paulo: Cortez, 201 1. (Coleção Questões da Nossa Época).

VÁZQUEZ, A.S. Ética. 37. ed. Tradução Dell'Anna, J. Rio de Janeiro: Civilização Brasileira, 2017.

Recebido em: 20 de dezembro de 2019

Aprovado em: 04 de março de 2020 